\title{
REVIEW
}

\section{Yttrium radiosynoviorthesis in the treatment of knee arthritis in rheumatoid arthritis: a systematic review}

\author{
Liesbeth L J Heuft-Dorenbosch, Henrica C W de Vet, Sjef van der Linden
}

\begin{abstract}
Objective-To consider the question: How strong is the evidence in favour of yttrium synovectomy in chronic knee arthritis in patients with rheumatoid arthritis in comparison with placebo and intraarticular steroid treatment?

Methods-A systematic review of the literature was performed using Medline and the Embase database.

Results-Initially, seven papers were identified, but only two met the inclusion criteria. Neither study showed evidence in favour of yttrium synovectomy.

Conclusion-From the point of view of evidence based medicine it should be seriously questioned whether yttrium synovectomy deserves a place in clinical practice.

(Ann Rheum Dis 2000;59:583-586)
\end{abstract}

In the treatment of rheumatoid arthritis (RA), local articular treatment has a place in persistent monarthritis or oligoarthritis, with or without disease controlling antirheumatic treatment. Thus the use of intra-articular corticosteroids is an important and widespread therapeutic intervention. If intra-articular steroid treatment in chronic monarthritis fails, synovectomy is sometimes considered. This local treatment can be achieved by surgical, chemical, or radiation techniques. Volkmann introduced surgical synovectomy of the knee in 1877. It was extended to other articulations in the 1950s and today it is still in use.

Chemical synovectomy has historically been tried with the help of various products, such as osmic acid, alkylating agents like nitrogen mustard and thio-tepa, methotrexate, and antibiotics. ${ }^{1}$ Eventually, nitrogen mustard, thiotepa, methotrexate, and antibiotics fell into disuse, although osmic acid is still occasionally used in some countries.

Synovectomy by radioisotopes was first tried in the 1950s and Delbarre introduced the term synoviorthesis for this treatment in $1968 .^{2}$ Synoviorthesis literally means the restoration (orthesis) of the synovia. The technique requires a radionucleotide with the appropriate characteristics. Ideally speaking, the radiophar-
Table 1 Characteristics of various radioisotopes

\begin{tabular}{lcll}
\hline Product & $\begin{array}{l}\text { Half life } \\
\text { (days) }\end{array}$ & Radiation & $\begin{array}{l}\text { Mean soft tissue } \\
\text { penetration }(\mathrm{mm})\end{array}$ \\
\hline Gold-198 & 2.7 & $\beta$ and $\gamma$ & 1.2 \\
Yttrium-90 & 2.7 & $\beta$ & 3.6 \\
Erbium-169 & 9.5 & $\beta$ & 0.3 \\
Rhenium-186 & 3.7 & $\beta$ and $\gamma$ & 1.2 \\
Phosphorus-32 & 14.3 & $\beta$ & 2.6
\end{tabular}

maceutical agent should have specific properties. ${ }^{3}$ The radiation energy should be sufficient to penetrate and ablate the synovial tissue, but not so great as to damage underlying articular cartilage or overlying skin. The radionucleotide should be attached to particles that are sufficiently small to be phagocytosed, but not so small that they might leak out of the joint before phagocytosis occurs. Furthermore, the particle should be biodegradable because otherwise granulomatous tissue might be induced. Usually, $\beta$ emitting radionucleotides are used, as $\alpha$ radiation has insufficient penetration and $\gamma$ radiation has too high a penetration. Various $\beta$ emitting radioisotopes are available, with different characteristics (table 1).

By far the most extensive experience with radioisotopes used for radiosynoviorthesis in RA has been obtained with radioactive yttrium-90 $\left({ }^{90} \mathrm{Y}\right)$, a pure $\beta$ emitter that is mostly used in the knee joint. ${ }^{4}$ Histological studies after yttrium synovectomy have shown reduction of the number and size of the synovial villi with decreased hyperaemia in the early phase, though thickening of the synovium often occurs. Later on, sclerosing and fibrosing processes of the synovial villous stroma predominate, together with minimum diffuse damage of the articular cartilage. Both filtration and resorption of the synovial fluid are reduced. A few months after treatment with the radioisotope, mononuclear cell infiltration in the synovia has disappeared and if the treatment is effective the synovium is fibrosed. ${ }^{5}$

Internationally, radiation synovectomy is not extensively performed and large differences in its use exist between countries - for instance, it is regularly practised in Australia and Canada but virtually non-existent in the Unites States. ${ }^{6}$ Historically, the clinical effectiveness of yttrium synovectomy has been much debated, and 
Table 2 Characteristics of identified studies

\begin{tabular}{lllll}
\hline First author & $\begin{array}{l}\text { Year of } \\
\text { publication }\end{array}$ & $\begin{array}{l}\text { No of } \\
\text { patients/knees }\end{array}$ & $\begin{array}{l}\text { Yttrium } \\
\text { dosage } \\
(m \text { Ci })\end{array}$ & Comparator \\
\hline Bridgman $^{12}$ & 1971 & $22 / 42$ & 3 & Placebo \\
Bridgman $^{13}$ & 1973 & $23 / 44$ & 3 & Placebo \\
Delbarre $^{14}$ & 1974 & $97 / 146$ & 6 & Placebo \\
Szanto $^{15}$ & 1977 & $33 / 58$ & $3-4$ & $\begin{array}{l}\text { Methylprednisolone acetate } \\
\text { Yates }^{9}\end{array}$ Arthritis and Rheumatism Council Multicentre $_{\text {Radiosynoviorthesis Trial Group }^{16}}$ \\
Grant $^{18}$ & 1979 & $28 / 33$ & 5 & $\begin{array}{l}\text { Placebo } \\
\text { Triamcinolone hexacetonide }\end{array}$ \\
\hline
\end{tabular}

conflicting data have been published..$^{7-9}$ If yttrium synovectomy is to be considered a clinically relevant intervention, it should be clearly more effective than placebo in its effect on pain and function. Moreover, because yttrium synovectomy is a more complex procedure, it should have important advantages compared with intra-articular corticosteroids.

In this paper we want to consider the following question. How strong is the current evidence in the literature of the efficacy of yttrium synovectomy in chronic knee arthritis in patients with established RA, particularly in comparison with intra-articular steroid treatment?

\section{Materials and methods}

We first checked the Cochrane library of systematic reviews to see whether a systematic review of the literature already existed. A review of yttrium synovectomy was found on the DARE database, ${ }^{10}$ but it was published before 1994 and had not yet been fully assessed as to whether it met the current DARE quality criteria. Thus we decided to perform a new systematic review using Medline and the Embase database. We also reviewed literature references of publications retrieved, including editorials. Medline was searched up to October 1999 , using the MESH terms yttrium and synovectomy, all headings and subheadings. This produced 94 papers. A second search was performed using the MESH terms yttrium and rheumat ${ }^{\star}$, all headings and subheadings. This showed 156 papers. 66 papers were identified in both searches, so a total of 184 different papers were identified. Similarly, in the Embase database 78 papers were located using the MESH terms yttrium and synovectomy, all headings and subheadings and 86 papers using the terms yttrium and rheumat*, all headings and subheadings. Because 51 papers were retrieved in both searches, this search yielded a total of 113 different papers.

For inclusion of the papers a two step procedure was followed. Firstly, papers were selected if yttrium was compared with placebo or intra- articular corticosteroids, the patient group consisted of patients with RA and persistent knee arthritis, the publication reported a randomised controlled trial (RCT), and publications were in Dutch, English, French, German, or Spanish. Secondly, the methodological quality of the RCTs found was assessed using the so-called Delphi List, ${ }^{11}$ a criteria list for quality assessment of RCTs. Finally, included were those papers that both met the selection criteria and also were considered to be of sufficient methodological quality based on the Delphi List.

\section{Results}

In Medline six papers were identified which met our inclusion criteria ${ }^{92-16}$ and one additional paper was identified in Embase. ${ }^{18}$ Thus seven papers were identified. Table 2 describes the characteristics of these seven studies in chronological order.

The two papers by Bridgman ${ }^{12} 13$ compared yttrium with placebo, the second paper presenting more definite data after 12 months. Only the latter study was included. The study by Szanto ${ }^{15}$ provided data on 33 patients with different forms of arthritis. Data of patients with RA were not presented separately and no information about randomisation or blinding was given. We decided not to include this study. This left five studies ${ }^{913141618}$ whose methodological quality was assessed by one of us (EHD). These studies are presented in chronological order (table 3).

The five remaining studies were scrutinised in more detail. The findings of the study by Delbarre $^{14}$ were presented in a complicated graphical way. We could not interpret these data in sufficient detail; therefore we did not include the data in this review. The study performed by Yates $^{9}$ was not included because of a lack of presented data. Only a general conclusion was given; Yates stated that "there was no significant difference in clinical indices between the two treatment groups". The ARC study ${ }^{16}$ was discontinued prematurely because of dwindling recruitment and therefore was

Table 3 Methodological features of identified studies as defined by the Delphi List ${ }^{11}$

\begin{tabular}{|c|c|c|c|c|c|c|c|c|c|}
\hline Author & Randomisation & $\begin{array}{l}\text { Treatment } \\
\text { allocation } \\
\text { concealed }\end{array}$ & $\begin{array}{l}\text { Baseline } \\
\text { similarity }\end{array}$ & $\begin{array}{l}\text { Eligibility } \\
\text { criteria } \\
\text { specified }\end{array}$ & $\begin{array}{l}\text { Outcome } \\
\text { assessor } \\
\text { blinded }\end{array}$ & $\begin{array}{l}\text { Care provider } \\
\text { blinded }\end{array}$ & $\begin{array}{l}\text { Patient } \\
\text { blinded }\end{array}$ & $\begin{array}{l}\text { Point estimates } \\
\text { and variability } \\
\text { presented }\end{array}$ & $\begin{array}{l}\text { Intention to } \\
\text { treat analysis }\end{array}$ \\
\hline Bridgman $^{13}$ & + & $?$ & + & - & + & $?$ & + & + & $?$ \\
\hline Delbarre $^{14}$ & + & ? & ? & - & $?$ & ? & $?$ & ? & ? \\
\hline Yates $^{9}$ & + & $?$ & $?$ & - & + & ? & $?$ & - & $?$ \\
\hline $\mathrm{ARC}^{16}$ & + & ? & + & + & + & ? & - & + & $?$ \\
\hline Grant $^{18}$ & + & + & + & + & + & + & + & + & ? \\
\hline
\end{tabular}

$+=$ yes; $-=$ no; $?=$ no information provided. 
Table 4 Outcome measures and results of the studies finally included

\begin{tabular}{llll}
\hline Author & Outcome measures & $\begin{array}{l}\text { Follow up } \\
\text { period } \\
\text { (months) }\end{array}$ & Significant difference at the end of the trial \\
\hline Bridgman $^{13}$ & $\begin{array}{l}\text { Knee circumference (inches) } \\
\text { Joint range (degrees) } \\
\text { Fixed flexion (degrees) } \\
\text { Pain (five point scale) } \\
\text { Subjective change (three point scale) } \\
\text { Knee effusion (five point scale) } \\
\text { Radiological assessment (No of erosions) }\end{array}$ & $\begin{array}{l}\text { Range of motion } \\
\text { and } \\
\text { Knee circumference (favouring yttrium v placebo) }\end{array}$ & \\
& $\begin{array}{l}\text { Pain at rest (five point scale) } \\
\text { Grant }{ }^{18}\end{array}$ & 6 & Range of motion (favouring triamcinolone $v$ yttrium) \\
& $\begin{array}{l}\text { Pain on walking (five point scale) } \\
\text { Joint tenderness (four point scale) } \\
\text { Range of movement (degrees) } \\
\text { Knee effusion (three point scale) } \\
\text { Patient overall assessment (three point } \\
\text { scale) }\end{array}$ & & \\
\hline
\end{tabular}

also not included in our study. The authors stated that "for what they are worth, the presented data do not lend support to the view that yttrium is more or less advantageous than triamcinolone hexacetonide".

Thus only two RCTs meeting our inclusion criteria provided sufficient details and did not have major methodological flaws and were, therefore, found suitable to answer our question. One study compared yttrium with placebo, ${ }^{13}$ the other, yttrium synovectomy with triamcinolone hexacetonide. ${ }^{18}$ Table 4 presents the results of these two studies.

In the study by Bridgman, 21 patients with arthritis in both knees, 15 of them rheumatoid factor positive, randomly received a modest dose of $3 \mathrm{mCi}{ }^{90} \mathrm{Y}$ in one knee joint and saline in the other in a double blind set up. Two patients with unilateral gonitis received ${ }^{90} \mathrm{Y}$ only. (The paper does not state whether this happened under blinded conditions.) Table 4 presents the outcome measures. Follow up time was 12 months. At that time, there was only a significant difference in joint range of motion and knee circumference in favour of ${ }^{90} \mathrm{Y}$, but no significant difference in pain, effusion, or subjective changes. Meaningful difference of joint range of motion was defined as a change of at least $10^{\circ}$. In the ${ }^{90} \mathrm{Y}$ group 13 of the 23 knees improved compared with none of the 21 knees in the saline group. Relevant change in circumference was defined as a change at the mid-patellar level of more than half an inch $(>1.27 \mathrm{~cm})$. Altogether, eight of the 23 patients improved in the ${ }^{90} \mathrm{Y}$ group compared with two of the 21 in the saline group. The study did not report any co-interventions or concomitant use of, or changes in, disease controlling antirheumatic treatment during the study period.

In the study by Grant $^{18} 30$ chronically inflamed knee joints of 22 patients with RA were injected under double blind conditions with either $8 \mathrm{mCi}{ }^{90} \mathrm{Y}$ or $20 \mathrm{mg}$ triamcinolone hexacetonide.

Baseline characteristics did not differ significantly between both groups. Table 4 presents the outcome measures. Both after one and six months of follow up the response of the triamcinolone group was better than that of the yttrium group, but the difference diminished with time. After one month there was a significant difference for pain, effusion, and range of motion, whereas after six months only a statistically significant difference in the range of motion of the knee joint persisted. In the triamcinolone group, the range of motion increased from a mean of $108.5^{\circ}$ to $122.4^{\circ}$. In the ${ }^{90} \mathrm{Y}$ group the range of motion did not improve and remained about $107^{\circ}$ both at baseline and at six months. In the subsequent six years of open follow up, no significant differences in the numbers experiencing therapeutic failure $v$ success were found between the two patient groups. During the study, more changes in disease controlling antirheumatic treatment were seen in the triamcinolone group. The authors stated that this did not explain the observed differences between the groups, because improvement in knee status was most marked before it was modified by second line treatment. Furthermore, the rate of improvement in the knee treated with triamcinolone was diminishing at the time when a response to modification of second line treatment would have been expected to affect the knee favourably. ${ }^{18}$

\section{Discussion}

Although radioactive yttrium $\left({ }^{90} \mathrm{Y}\right)$ is often used in the treatment of patients with chronic knee synovitis, there is little support from RCTs for this form of treatment. Most results reported are based on observations in nonrandomised, heterogeneous patient groups ${ }^{319} 20$ and might have been biased in several ways. The studies included in our review, which were of sufficient methodological quality, show no clear evidence of the efficacy of yttrium synovectomy.

In the study by Bridgman, ${ }^{13}$ yttrium had no statistically significant effect on pain as an outcome measure, though it has to be noted that the dose of $3 \mathrm{mCi}$ used was relatively modest. In addition, it might be questioned whether the reported statistically significant improvement in range of motion and circumference was really a relevant clinical improvement. In the study by Grant $^{18}$ triamcinolone was better than yttrium in improving the range of motion of the knee joint, despite the modest dose of $20 \mathrm{mg}$ of triamcinolone hexacetonide that was used and the relatively high dose of $8 \mathrm{mCi}$ of yttrium. ${ }^{6}$ The initially better effect of triamcinolone on pain did not persist during the six months' 
observation period. Both studies included only small numbers of patients.

The meta-analysis on yttrium synovectomy in the knee published in 1993 by Jones ${ }^{10}$ included eight studies. ${ }^{7}{ }^{13151621-23}$ Five of these studies did not meet our inclusion criteria. One study had only been published as a concise abstract, ${ }^{7}$ another study was done in a patient group with different forms of arthritis, ${ }^{15}$ and three studies compared yttrium with forms of treatment other than placebo or steroids. ${ }^{21-23}$ Finally, one study did not include controls. ${ }^{8}$ Jones also included the discontinued ARC trial, ${ }^{16}$ which was excluded by us. The study by Bridgman $^{13}$ was included in both his and our review. Overall, in the meta-analysis by Jones the conclusion was that "a significant difference was found between yttrium and placebo despite the small number of patients studied, suggesting a strong effect" but "only one negative unpublished trial would be necessary to have negated this significant result". $\mathrm{He}$ concluded that "only a trend towards improvement was suggested comparing yttrium to triamcinolone in favour of yttrium and for yttrium $v$ other modalities there was no trend in either direction".

The present review indicates that it should be seriously questioned whether yttrium synovectomy deserves a place in clinical practice from the point of view of evidence based medicine. Justifying the continuation of yttrium synovectomy would require much stronger evidence in favour of this form of treatment.

Such evidence might result from a trial with the following design: an RCT comparing four groups, one group receiving yttrium, one group receiving corticosteroids, one group receiving only placebo, and one group receiving both yttrium and corticosteroids concomitantly. In clinical practice, corticosteroids are often given together with intra-articular yttrium. The results of the study by Grant support the view that the therapeutic effect might depend on this concomitant administration of steroids rather than the administration of yttrium alone. In the proposed study pain and function should be regarded as primary outcome measures. Furthermore, objective assessment of the extent of synovitis before and after the procedure, with the help of newer, non-invasive techniques such as magnetic resonance imaging or ultrasound, can give important additional information and should be considered in any study on this subject. Close attention should be paid to any change in disease controlling antirheu- matic treatment during the observation period and also, long term effects, such as premature osteoarthritis, should be monitored. In addition, the cost effectiveness of the procedure should be considered.

1 Cruz-Esteban C, Wilke WS. Non-surgical synovectomy. Ballieres Clin Rheumatol 1995;9:787-801

2 Delbarre F, Cayla J, Menkes C, Aignan M, Roucayrol JC, Ingrand J. La synoviothese par les radio-isotopes. Presse Med 1968,76:1045-50.

3 Müller W, Pavelka K, Fridrich R. Treatment of chronic articular effusions with 90-yttrium. Scand J Rheumatol 1975;4:216-20.

4 Clunie G, Ell PJ. A survey of radiation synovectomy in Europe. Eur J Nucl Med 1995;22:970-6.

5 Mödder G. Radiosynoviorthesis. Involvement of nuclear medicine in rheumatology and orthopaedics. Meckenheim, Germany: Warlich Druck und Verlagsges mbH, 1995.

6 Deutsch W, Brodack JW Deutsch KF. Radiosynovectomy revisited. Eur J Nucl Med 1993;20:1113-27.

7 Menkes C, Le Go A, Verrier P, Delbarre F. A contolled trial of intra-articular yttrium-90, osmic acid and triamcinolone hexacetonide in rheumatoid arthritis [abstract]. XIV Congress Rheumatology San Francisco, Maryland, USA: LipCongress Rheumatology San Francisco, Maryl
pincott Williams and Wilkins 1977:614.

pincott Williams and Wilkins 1977:614.
8 Boerbooms AM, Buijs WC, Danen M, van de Putte Boerbooms AM, Buijs WC, Danen M, van de Putte
LB,Vandenbroucke JP. Radio-synovectomy in chronic $\mathrm{LB}$,Vandenbroucke JP. Radio-synovectomy in chronic
synovitis of the knee joint in patients with rheumatoid synovitis of the knee joint in patients with
arthritis. Eur J Nucl Med 1985; 10:446-9.

9 Yates DB, Scott JT, Ramsey N. Double-blind trial of ${ }^{90} \mathrm{Y}$ for chronic inflammatory synovitis of the knee. Rheumatol Rehabil 1979;suppl:46-7.

10 Jones G. Yttrium synovectomy: a meta-analysis of the literature. Aust NZ J Med 1993;23:272-5.

11 Verhagen A, de Vet H, de Bie R, Kessels A, Boers M, Bouter L, et al. The Delphi List: a criteria list for quality assessment of randomized clinical trials for conducting systematic reviews developed by Delphi consensus. J Clin Epidemiol 1998;51:1235-41.

12 Bridgman JF, Bruckner F, Bleehen NM. Radioactive yttrium in the treatment of rheumatoid knee effusions. Ann Rheum Dis 1971;30:180-2.

13 Bridgman JF, Bruckner F, Eisen V, Tucker A, Bleehen NM Bridgman JF, Bruckner F, Eisen V, Tucker A, Bleehen NM.
Irradiation of the synovium in the treatment of rheumatoid Irradiation of the synovium in the tre
arthritis. Q J Med 1973;42:357-67.

14 Delbarre F, Le Gô A, Menkes C, Aigan M. Preuve par étude statistique "en double aveugle" de l'effet thérapeutique d'un colloide chargé d'yttrium radioactif $\left({ }^{90} \mathrm{Y}\right)$ dans l'arthrite rhumatoïde du genou. C R Acad Sci Hebd Seances Acad Sci D 1974;279:1051-4.

15 Szanto E. Long-term follow-up of ${ }^{90}$ Yttrium-treated kneejoint arthritis. Scand J Rheumatol 1977;6:209-12.

16 Arthritis and Rheumatism Council Multicentre Radiosynoviorthesis Trial Group. Intra-articular radioactive yttrium and triamcinolone hexacetonide: an inconclusive trial. Ann Rheum Dis 1984;43:620-3.

17 Withdrawn.

18 Grant EN, Bellamy N, Fryday-Field K, Dinsey T, Driedger A, Hobby $\mathrm{K}$, et al. Double-blind randomized controlled trial and six-year open follow up of yttrium-90 radiosyntrial and six-year open follow up of yttrium-90 radiosyn-
ovectomy versus triamcinolone hexacetonide in persistent ovectomy versus triamcinolone hexacetonide in persistent
rheumatoid knee synovitis. Inflammopharmacology 1992; $1: 231-8$.

19 Reichel H, Bergmann H, Kolarz G,Thumb N. Die radiosynoviorthese mit yttrium-90-silikat. Acta Med Austriaca 1979;6:19-25

20 Vignon G, Colcombet Ph, Lahneche B, Bied J-C, Meunier P. Comparaison des synoviortheses osmiques et isotopiques dans la polyarthrite rhumatoide. La Nouvelle Presse Medicale 1974;3:2712-14.

21 Sheppeard H, Aldin A, Ward DJ. Osmic acid versus Yttrium-90 in rheumatoid synovitis of the knee. Scand J Rheumatol 1981;10:234-6

22 Nissilã $M$, Antilla $P$, Hãmãlãinen $M$, Jalava S.Comparison of chemical, radiation and surgical synovectomy for knee joint synovitis. Scand J Rheumatol 1978;7:225-8.

23 Gumpel JM, Roles NC. A controlled trial of intra-articular radiocolloids versus surgical synovectomy in persistent synovitis. Lancet 1975;i:488-9. 